\title{
Ensino Policial na Academia Integrada de Defesa Social: Instrução militar e
}

\author{
profissionalidade docente em foco
}

\section{Police Education in the Integrated Academy of Social Defense: Military education and teaching professionalism in focus}

\author{
Benôni Cavalcanti Pereira, Kátia Maria da Cruz Ramos \\ Universidade Federal de Pernambuco
}

\begin{abstract}
Resumo
No cenário de avanço da criminalidade no Brasil, impõese às Instituições Policiais a necessidade de revisão dos parâmetros formativos. Objetivou-se caracterizar elementos estruturantes da profissionalidade docente requerida para atuar na formação policial no contexto das exigências do paradigma preventivo e do ensino policial. Os dados obtidos junto aos formadores atuantes no curso, através de questionário e entrevista semiestruturadas e analisados quanto à profissionalidade docente requerida, revelaram que a profissionalidade docente requerida, ao mesmo tempo em que ainda se encontra vinculada a elementos estruturantes da figura do instrutor, caminha para uma (re)configuração na direção do status docente. Palavras-chave: profissionalidade docente, ensino policial, instrução militar.
\end{abstract}

\begin{abstract}
In the scenario of advancing crime in Brazil, the Police Institutions need to review the training parameters. The objective was to characterize structuring elements of the teaching professional required to act in the police training in the context of the requirements of the preventive paradigm and police education. The data obtained from the trainers working in the course, through a semistructured questionnaire and interview and analyzed as to the required teaching professionalism, revealed that the required teaching professionality, while still being linked to structuring elements of the instructor figure, moves towards a (re)configuration toward teacher status.

Keywords: Teacher professionalism, police training, military instruction.
\end{abstract}

A escalada da criminalidade e da violência social ao longo dos anos no Brasil impôs às Instituições de Defesa Social a imprescindível necessidade de revisão dos seus parâmetros de formação e reflexão da atuação de seus profissionais frente às comunidades. Inclusive, importou considerar o relevante papel do formador no ensino policial, pois cabe ao instrutor o exercício da função docente, no sentido mais amplo, ou seja, a ação de ensinar à função policial.

Partiu-se do pressuposto de que a atual concepção do formador como instrutor, sustentada como mero transmissor de informações, centrado na sua reconhecida experiência profissional traduz sérios riscos aos avanços pretendidos no ámbito da formação profissional e do emergente ensino policial. Neste sentido, a pesquisa teve como foco de atenção os elementos estruturantes daquele que tem a função de ensinar à profissão policial, ou seja, o instrutor/formador atuando como docente no ámbito do emergente ensino policial.

E, nesse quadro, organizou-se este artigo a partir dos resultados da pesquisa qualitativa desenvolvida no ámbito do Programa de Pós-graduação em Educação (PPGE) da Universidade Federal de Pernambuco (UFPE), começando pela contextualização da temática tecendo considerações acerca do ensino policial diante da transição paradigmática na segurança pública, trazendo à tona a questão da formação policial e a pertinência do debate em torno da profissionalidade docente. Em seguida, o caminho metodológico trilhado pela investigação, indicando, a partir dos instrumentos escolhidos, a discussão dos resultados e as considerações finais sobre os resultados de pesquisa e seus contributos.

\section{O ensino policial na transição paradigmática das ações de segurança pública}

A busca pela superação do paradigma repressivo e a afirmação de um novo paradigma para segurança pública (BENGOCHEA, 2005) vai incidir diretamente em novas políticas de formação policial (MUNIZ, 2001) implicando numa transformação que vai desembocar no atuação do formador deste profíssional. Estas questões em torno da formação tem a intenção de aprimorar sua atividade e elevar seu status profissional, o que não parece ter sentido sem rever a profissionalidade do formador, sob pena de ficar fragilizados na sua operacionalização.

Kuhn (1962) popularizou o termo paradigma, apresentando noções de paradigma em diferentes abrangências, afirmando que são sempre posições, ideias e procedimentos de verificação de conhecimento, compartilhados num contexto historicamente datado. Assim, entender-se-á, neste texto, por paradigma, um padrão de comportamento e concepção de atuação 
policial compartilhado por seus membros, num determinado contexto histórico.

Há diversas denominações atribuído ao modelo de polícia tradicional, desde burocrático-militar até o da aplicação da lei ou law enforcement, contudo, todos eles são afetos ao conhecido paradigma repressivo de atuação da polícia, ao qual se pretende superar. Enquanto as novas denominações que surgem para caracterizar esta nova polícia seguem-se desde polícia comunitária até polícia cidadã (BENGOCHEA, 2005), os quais são atinentes ao que se conhece por paradigma preventivo, ao qual se pretende afirmar no novo contexto social.

Para Bayley (2002) e Monjardet (2003), o modelo de polícia orientado para repressão não é mais eficiente na resolução dos problemas sociais, isto requer uma mudança no trabalho policial, em sua estrutura e formação dos seus profissionais. Para que esta transformação se concretize, segundo Muniz (2001) é preciso uma mudança de paradigma, de um modelo repressivo que parece não respeitar os valores de cidadania, para um modelo mais efetivo e de caráter preventivo, como garantia de um Estado Democrático de Direito que visa, entre outras, a proteção da sociedade.

Em meio à transição paradigmática, vem emergido o debate do ensino policial (BRASIL, 2001 e 2003; SOUZA, 2003), a partir do qual foi considerado oportuno trazer o debate para o ámbito da profissionalidade docente, em termos de avanços esperados na atuação do formador deste profissional de segurança pública.

\section{Recorrendo à noção de profissionalidade docente para situar o caráter do formador no ensino policial}

Considerando que o formador se constitui num dos elementos centrais desse processo de mudança na formação policial, acreditou-se na pertinência de realizar estudos acerca da profissionalidade docente requerida para atuar na formação desse profissional.

Outrossim, o reconhecimento da docência no ensino policial estabelece uma estreita relação entre a ação de ensinar e o papel do formador. Logicamente, o entendimento sobre termo docência segue a própria etimologia, como nos apresentou Veiga (2005, p.39) "significa ação de ensinar, e está vinculado ao radical do verbo latino docere, cujo sentido se expressa por ensinar, instruir, [...]". Isto posto por se saber que a docência pode ser abordada por outros ângulos, mas em perder de vista seu significado.

Outro dado importante presente nas pesquisas de Veiga (2005) foi a percepção de termos correlatos, observando que a instrução - compreendida como ação de transmitir - traduz vínculos com o significado da docência, assim como os termos instrutor e docente. Esta ligação com o termo docência desde idos da instrução militar indicam a presença da profissionalidade docente, mesmo que restrita consoante a distinção proposta por Hoyle (1980). Inclusive, este é um assunto que será retomado mais adiante.

Pensando nesse contexto da profissionalidade, Dubar (1987) vai trazer este debate para o campo da articulação entre a qualificação e a competencia, demostrando que a profissionalidade contempla a competência feita de um corpo de saberes interiorizados e o saber-fazer aliada a qualificação atestada pelos títulos.

No exemplo exposto por Dubar (1987, p.09), na relação levantada entre o lugar do profíssional nas concepções de qualificação e competência, faz um paralelo entre os resultados da análise de Monjardet sobre a ação policial e de Demailly sobre as transformações da profissão docente, pontuando duas afirmações instigantes:

[...] a qualificação jurídica atestada e hierarquizada pelos títulos escolares, e garantia duma profissionalidade de tipo científico tradicionalmente associada à missão de instrução e de transmissão de saberes disciplinares no ensino, ela aparece ligada a uma concepção mais repressiva que preventiva da acção policial (fazer respeitar a lei, combater o banditismo...).

[...] os policiais, que consideram sua profissão como a implementação de qualificações técnicas, insistem sobre a posse prévia de um "saber rigoroso e preciso" em matéria de legislação e de "técnicas policiais": segundo eles, o policial "incompetente" é, antes de mais nada, um ignorante que não recebeu os conhecimentos formais imprescindíveis ao exercício de sua atividade concebida como instauração de uma ciência.

Esse movimento em torno das concepções de qualificação e competências nos remetem à reflexão em torno das qualificações exigidas do formador para exercício da docência no ensino policial e, ao mesmo tempo, implicações no desenvolvimento da competência acerca da ação de ensinar.

No caso do atual contexto de transição paradigmática no campo da segurança pública, ao mesmo tempo tempo em em que se incorporaram novos conhecimentos à profissão policial, estava também se alterando a profissionalidade do formador desse novo policial. Nessa linha de raciocínio, a formação apresenta-se com maior complexidade, exigindo da competência do formador diante dos novos parâmetros formativos advindos da concepção mudança da mera instrução militar para ensino policial.

Sendo sabedor dos movimentos e debates acerca da profissionalização e do estatuto da profissionalidade plena do docente, é importante salientar que a pesquisa se manteve alinhada como o esforço explicitado por Roldão (2007, p.97), ou seja, em torno da clarificação da função de ensinar, envolvendo a ligação entre "a natureza da função e o tipo de conhecimento específico que se reconhece como necessário para exercê-la”.

A respeito da profissionalidade dos docentes e do processo de desenvolvimento profissional no melhoramento da qualidade da profissionalidade, Hoyle (1980) faz uma caracterização e distinção entre profissionalidade restrita e profissionalidade extensa, onde a primeira tende a focalizar mais a sala de aula e se basear mais pela experiência em vez da teoria e tende para não perceber as atividades da sua sala de aula dentro de um contexto educacional mais amplo, justamente o contrário da segunda, por se interessar por este contexto, pela teoria e desenvolvimentos 
educacionais mais recentes, promovendo seu próprio desenvolvimento profissional através do trabalho.

Diante disso, a figura do formador na instrução militar aproxima-se bastante das características de uma profissionalidade restrita, ao tempo em que se passou a exigir do formador, no ámbito do emergente ensino policial uma profissionalidade extensa, com vistas a uma visão mais holística da ação de ensinar. Isso fica mais visível após o surgimento das políticas nacionais para ações formativas dos profissionais de segurança pública (BRASIL, 2001 e 2003). Recorrer aos estudos em torno da profissionalidade docente, portanto, no campo da formação policial, justifica-se pois não se almeja mais meros procedimentos de trânsmissão da instrução militar, mas sim de toda complexidade que envolve a ação de ensinar.

A afirmação do paradigma preventivo trouxe consigo, portanto, a mudança da instrução militar para o ensino policial, contudo não se pode perder de vista as implicações desta mudança na profissionalidade dos formadores, pois como pontuou Sacristán (1995, p.66), "o ensino é uma prática social, não só porque se concretiza na interação entre professores e alunos, mas também porque estes atores refletem a cultura e contextos sociais a que pertencem”. Tudo isto se dá em meio ao contexto histórico e social e a natureza do conhecimento em legitimação, por isso é importante entender a profissionalidade docente como um conceito em permanente elaboração.

Roldão (2007) contribui para a análise das questões sobre a profissionalidade docente, reforçando seu caráter dinâmico a partir dos conceitos, papéis e funções sociais e profissionais ao longo dos tempos e conforme o contexto em que se vive. Quanto ao entendimento por ensinar, Roldão (2005) entende que é a ação docente de fazer aprender alguma coisa a alguém, mas expõe que não há consenso estabelecido, ou ainda, que há duas leituras distintas: como professar um saber ou como fazer outros se apropriarem de um saber.

\section{Importância de alguns estudos encontrados}

Alguns autores pesquisaram anteriormente a formação policial e foram importantes para sinalizar lacunas em trono do fenómeno estudado e auxiliar na interpretação dos dados pesquisados. Basílio (2007), por exemplo, destacou a necessidade de mudança do perfil reativo para proativo, apontando várias preocupações, entre elas, a questão da capacitação dos instrutores, identificando uma seleção inadequada e muitos relatos sobre a falta de compatibilidade com a função, contudo, sem maiores aprofundamentos de pesquisa. Jacondino (2011) apontou para necessidade de rever instrumentos da formação policial, mais adaptáveis a essa realidade sem, contudo, adentrar no mérito da questão, preocupando-se com o regime disciplinar da polícia militar como limitador.

Em termos dd formação mais profissional do policial, Poncioni (2005) foi pioneira e, embora tenha focado no estudo curricular, seus resultados permitiram reflexões acerca profissionalidade exigida do formador diante do novo perfil policial almejado pela sociedade.
Já a pesquisa realizada por Veras (2008) chamou atenção, pois teve como objeto de estudo a docência na Polícia Militar do Ceará, investigou a prática pedagógica dos formadores e sua articulação com as novas diretrizes de formação numa filosofia de segurança cidadã. Seus resultados demonstraram que professores militares manifestavam a defesa da prática pedagógica baseada na transmissão do conhecimento bem como metade dos professores civis, enquanto a outra metade creditavam a uma postura mais aberta ao diálogo e proximidade junto aos alunos. Estes estudos reforçaram o interesse e o caminho trilhado.

\section{Caminhos metodológicos trilhados}

A pesquisa assumiu a abordagem qualitativa com vista a uma maior profundidade, não se resumindo apenas a descrição do fenômeno, mas também elementos explicativos, sendo mais adequado para caracterizar elementos estruturantes da profissionalidade requerida para atuar no ensino policial.

\section{Caracterização do espaço da pesquisa}

A pesquisa foi desenvolvida na Academia Integrada de Defesa Social (ACIDES), criada em 2005, iniciandose assim um processo de estruturação e integração das ações de formação no âmbito da Secretaria de Defesa Social do Estado de Pernambuco (SDS/PE). Surgiu com vistas a ser uma referência, em termos educacionais, na área de Defesa Social tendo recebido através do Parecer no 33/2008-CES, do Conselho Estadual de Educação de Pernambuco (CEE/PE), seu credenciamento como IES, passo considerado importantíssimo na construção de uma sólida e reconhecida política pública de formação dos seus profissional no Estado de Pernambuco, Brasil.

$\mathrm{O}$ espaço da pesquisa tratou-se específicamente do Campus de Ensino Mata da ACIDES, local de funcionamento do Curso de Formação de Oficiais da Polícia Militar (CFO/PM), no Estado de Pernambuco, Brasil.

É importante situar que o surgimento da Matriz Curricular Nacional (MCN) pautada na preocupação precípua quanto à formação, qualificação e valorização dos profissionais da área da segurança pública, enquanto política nacional de segurança pública (Brasil, 2003), estimulou reformas substanciais nas políticas formativas de segurança pública no Estado de Pernambuco, até mesmo porque seu objetivo precípuo era garantir uma unidade de pensamento e ação dos profissionais de segurança pública que serão formados pelas Academias e Centros de Ensino dos Órgãos de segurança pública de todo o Brasil.

\section{Sujeitos da pesquisa e instrumentos}

A escolha pelo CFO não foi aleatória, deu-se por se tratar da mais alta porta de entrada na Corporação Policial Militar, passando à condição de formação profissional no contexto da ACIDES. Assim, os sujeitos envolvidos nesta pesquisa realizada no ámbito do Mestrado em Educação entre os anos de 2012 e 2013, foram os instrutores que atuaram como formadores no $\mathrm{CFO} / \mathrm{PM}$, cuja malha curricular sofreu significativas 
mudanças ao longo das implantações das novas políticas formativas.

O primeiro instrumento - questionário - foi aplicado junto a 44 (quarenta e quatro) formadores (identificados com letra $\mathrm{F}$, seguido do número correspondente) e o segundo instrumento - entrevistas - deu-se com 09 (nove) destes formadores, para se aprofundar mais na busca dos objetivos de pesquisa, sob criterios de maior e menor experiencia operacional e como instrutor.

$\mathrm{Na}$ tabela abaixo percebe-se que $84 \%$ dos formadores situam-se acima dos 16 (dezesseis) anos de serviço e mais de $40 \%$ deles detêm mais de 20 anos de atuação, ou seja, carregam uma carga significativa de experiência técnico-profissional no âmbito da SDS.

Tabela 1.

Tempo de serviço dos formadores na SDS

\begin{tabular}{llc}
\hline Tempo de Serviço & Frequência & Percentual \\
\hline Menos de 05 anos & 1 & $2 \%$ \\
Entre 05 e 10 anos & 2 & $5 \%$ \\
Entre 11 e 15 anos & 4 & $9 \%$ \\
Entre 16 e 20 anos & 19 & $43 \%$ \\
Entre 21 e 25 anos & 10 & $23 \%$ \\
Mais de 26 anos & 8 & $18 \%$ \\
\hline TOTAL & $\mathbf{4 4}$ & $\mathbf{1 0 0 , 0 0 \%}$ \\
\hline
\end{tabular}

Quanto à formação ou nível de escolaridade, a tabela a seguir possibilita uma visão mais ampla da realidade de aperfeiçoamento do quadro de especialista da ACIDES que atuou na formação policial dos Oficiais da PMPE:

Tabela 2 .

Nivel de Escolaridade dos Formadores

\begin{tabular}{lll}
\hline Escolaridade/Formação Concluída & Frequência & Percentual \\
\hline Apenas CFO & 1 & $2 \%$ \\
Apenas Graduação & 3 & $7 \%$ \\
Especialização na área de Educação & 14 & $32 \%$ \\
Especialização na área de Segurança & 12 & $27 \%$ \\
ou Gestão Pública & & $18 \%$ \\
Especializações noutras áreas & 8 & $14 \%$ \\
Mestrado & 6 & $0 \%$ \\
Doutorado & 0 & $100 \%$ \\
\hline TOTAL & 44 & \\
\hline
\end{tabular}

A tabela 2 permitiu observar indícios da preocupação com a progressão do nível de escolaridade e da formação dos formadores, indicadores que possibilitam perceber a concentração forte na questão da pósgraduação lato sensu, em especial, na área de Educação. Além disso, o indicativo do alcance do nível de mestrado - pós-graduação (Strito Sensu) - entre esses formadores da ACIDES. Essa realidade acadêmica do corpo docente da ACIDES representada no gráfico já refletia a busca pela qualificação por parte do seu banco de especialistas, em especial pela área de educação, possivelmente fruto das políticas de valorização do ensino no âmbito da ACIDES e mudanças paradigmáticas na função policial.

\section{Resultados e discussão}

É importante ressaltar a relevância de dar voz aos sujeitos no ensino policial, no que diz respeito à atividade de formador, onde se confirmou uma tendência a superar a visão de instrutor militar, conforme se observou nos depoimentos abaixo apresentados.

A necessidade, de nos aperfeiçoarmos melhor para uma nova realidade no processo de ensino e aprendizagem (F.18).

A constante abertura aos conhecimentos e saberes novos que os atores envolvidos demonstram. Porque a temática da segurança pública exige das pessoas envolvidas na questão docente uma constante atualização (metodológica e conteudista) (F.27).

A capacidade do instrutor além do conhecimento cientifico no assunto que vai ser ministrado a capacidade como docente em termos pedagógicos dentro da sala de aula, de aplicações de dinâmicas mais eficientes $e$ adequadas para o ensino profissional na área de polícia (F.21)

Essas falas conduziram à intepretação de que o próprio formador, seja ele dotado de mais ou menos tempo operacional, de maior ou menor conhecimento especializado na sua área de atuação como formador, já percebia o movimento de transformação no seu papel no âmbito do ensno policial da ACIDES e que precisa de novas competências, não mais como mero instrutor perspectivado por modelo de instrução militar, mas agora como docente no ensino policial. Isto porque responderá às demandas que estão emergindo ligadas às novas situações pedagógicas concretas do ensino policial, cuja requesito anterior tornava-se insuficiente em termos do exigido nas novas atribuições postas pela estrutura das políticas nacionais para ações formativas.

Nesse quadro na transição paradigmática em que se situou este estudo, passou a ser exigido do policial, ao mesmo tempo, respeitar os direitos humanos, seguir as normas e protocolos de ação policial, bem como identificar e escolher suas alternativas práticas de atuação em função das situações encontradas, mobilizando conhecimentos desenvolvidos na sua formação e consolidados na sua prática e vivência, e não só no seu contexto profissional restrito, mas no social mais amplo (BRASIL, 2001; 2003).

No que diz respeito aos elementos estruturantes, tendo por referência os caracterizadores indicados por Roldão (2007), identificamos um reconhecimento de dimensões do trabalho docente que extrapola a condição única do conhecimento técnico-operacional - indicando possibilidades de (re)configuração da profissionalidade docente dos formadores que atuam no ensino policial na ACIDES. Isso porque havia consciência de uma nova realidade social, que impôs mudanças e novas exigências ao docente do ensino policial, como consta em depoimentos com este:

Primeiramente ele tem que chegar na sala de aula sendo bem entendedor dessas mudanças sociais, segundo ele também tem que entender que o público ao qual hoje nós 
trabalhamos, quer seja a sociedade quer seja os nossos alunos dentro de sala de aula, é um outro público, é um público mais questionador, muito mais crítico, em compensação isso vai cobrar e exigir do professor e do instrutor uma melhor qualificação (F.39).

Isso se encontrava ratificado quando considerava que, ao mesmo tempo em que se necessitava de qualificação na área da disciplina, saindo de uma concepção apenas conteudinal, o formador precisava saber exercer a função de ensinar balizado por um corpo de conhecimento, que, nos dizeres de Roldão (2007), é compósito e parte da relação dinâmica da qualificaçãocompetência.

Nesse caso, esse dado indicou possibilidades de (re)configuração da profissionalidade ao ter implícito que a qualificação é sempre, ao mesmo tempo, feita de um corpo de saberes interiorizados e um conjunto de saberes-fazer objetivados pela formação assegurada por títulos e pela experiência social incorporada dentro de esquemas profissionais (DUBAR, 1987; DEMAILLY, 1987; BRAEM, 2000). Abaixo a fala de um formador que congregou reflexões em torno dos conhecimentos dessa possibilidade:

Tem que ter um conhecimento adquirido na área técnica, na área de ensino, ele tem que ter um curso de graduação, no minimo, que lhe qualifique, ele tem que ter experiência e tem que ter paciência para poder tentar facilitar o trabalho dentro da sala de aula, direcionando para atividade que aquele profissional vai desenvolver. Disciplinas que exigem um pouco de prática, acredito que o policial essencialmente deve ter experiência de rua para poder adaptar esse conhecimento a uma realidade que o policial vai enfrentar no futuro bem próximo, então ele tem que ter essa experiência de campo (F.41).

No que se refere aos desafíos, é importante que se alerte sobre o papel de atuação institucional da ACIDES, na relação com possibilidades de (re)configuração da profissionalidade docente, principalmente diante de elementos limitadores expressos na organização institucional, em termos de descontinuidade de atuação como formador, conforme os anunciados:

[...] na verdade é questão de conciliar o ensino a docência com a nossa atividade rotineira aqui nas instituições, no meu caso aqui na SDS, porque conciliar essas duas coisas está sendo complicado porque sempre há a vontade de estar capacitando, repassando informações, mas também há necessidade de haver o cumprimento das atividade na seção que a pessoa é responsável seja na unidade operacional seja na unidade administrativa (F.21).

a natureza da atividade do policial militar existe alguns valores que estão arraigados na atividade policial militar que são valores ainda muito próximos da formação militar do exército que existe um sentimento que há uma necessidade que alguns desses valores sejam mantidos como a hierarquia, a disciplina, que são os pilares, que são considerados os pilares básicos da atividade policial militar então esse é um sentimento que ele está presente em todas as gerações dos militares que compõem por exemplo a polícia militar de Pernambuco (F.17).
Diante do exporto, no que se refere a concepções encontradas, elementos estruturantes e desafios enfrentados, podemos afirmar que os dados indicam possibilidades de reconfiguração da profissionalidade docente de formadores que atuam na ACIDES, seja do ponto de vista de expressarem uma profissionalidade docente requerida, em termos de vivência que aponta elementos de transição, seja por apontarem para uma profissionalidade docente requerida, em termos propositivos, que congrega elementos dessa transição.

Isso porque, como nos ensina Roldão (2005), pelo fato da função de ensinar se caracterizar pela dupla transitividade e pelo lugar de mediação, para além dos desafios de ordem institucional, não se pode ignorar o peso que constitui o ensino policial no que se refere à atuação do formador. Isso de forma a consolidar o reconhecimento das diversas dimensões que envolvem tal função em articulação com o devido apoio institucional para realizar o ato de ensinar à função policial no contexto da transição paradigmática.

Nesse sentido, a profissionalidade docente requerida ao mesmo tempo em que ainda se encontra preenchida com elementos estruturantes da figura do instrutor, caminha para uma (re)configuração na direção do status docente visto que o ensino policial começa a se desvincular da questão de ser tradicionalmente associada à missão de instrução, passando ainda pela transmissão de saberes disciplinares mas já se reconhecendo a necessidade de avançar em torno de um corpo de conhecimento complexo e dinâmico que é exigido daquele que exerce a função de ensinar.

\section{Considerações iniciais}

Tratar das inquietações acerca dos conhecimentos que foram incorporados à formação policial, exigindo-se ações formativas mais complexas, levou a refletir bastante sobre implicações na atuação do formador desse profissional, e o que de fato estava sendo requerido do formador, tido como docente do ensino policial.

Esse reconhecimento da docência no ensino policial evidenciou a exigência de um corpo complexo de conhecimentos para o exercício da profissão policial e, consequentemente, o reconhecimento de uma profissionalidade docente do formador, no sentido de que ensinar não se reduz à mera transmissão $\mathrm{e}$ reprodução de conhecimento.

A pesquisa revelou que os formadores estruturavam sua atividade formativa no âmbito da ACIDES a partir de um corpo de conhecimentos: técnico-operacional, especializado (conteudinal), didático-pedagógico e experiencial (atividade como formador). Embora com relevância ao conhecimento especializado, evidenciou o reconhecimento de outras dimensões para balizar suas ações formativas e que há também uma emergente preocupação com a aproximação com o conhecimento didático-pedagógico, evidenciando o reconhecimento da necessidade de desenvolvimento da função de ensinar em superação à mera instrução militar. Os formadores não só conseguiam compreender o ensino policial no contexto de sua atuação como também nas relações com 
os contextos, problemas e com a própria gestão realizada pela ACIDES, não se resumindo apenas a seu papel no momento das atividades formativas.

Os formadores elegeram como desafios a busca por conhecimentos específicos da docência, superação das dificuldades enfrentadas diante do paradigma repressivo ainda presente no âmbito do sistema de ensino da ACIDES, enquanto gestora do ensino policial em Pernambuco, Brasil, como elementos representativos para efetivação da mudança perspectivada pela afirmação do paradigma preventivo.

Neste caso, ressalta-se que para desenvolver uma nova profissionalidade docente, em oposição a um antigo modelo baseado na instrução militar, é preciso reconhecer e investir nesse embrionário processo de construção de um sistema próprio de ensino policial, legitimado internamente, a partir de um novo modo de formação dos formadores, mais próximo das realidades sociais, enfrentando as resistências postas nesse processo de superação do paradigma repressivo e de afirmação do paradigma educativo. Tudo isso no sentido de oferecer novos caminhos no enfrentamento aos desafios postos à segurança pública, com intuito de transformar a policía tida como repressiva, por intermédio do ensino policial, numa preventiva com viés educativo, sem perder de foco o seu maior objetivo institucional: a paz social e o bem-estar dos indivíduos na nossa sociedade.

\section{Referencias}

Basílio, Marcio Pereira. O desafio da formação do Policial Militar do Estado do Rio de Janeiro: utopia ou realidade possível? Dissertação de Mestrado em Administração pública, apresentada a EBAPE/FGV, 2007, 216pp.

Bayley, David. Padrões de policiamento: uma análise internacional comparativa. Tradução de René Alexandre Belmonte. $2^{a}$ Ed. São Paulo: Universidade de São Paulo, 2002.

Bengochea, Jorge Luiz Paz et al. A Transição de uma Polícia de Controle para uma Polícia Cidadã. São Paulo em perspectiva, São Paulo, v.18, n.1, mar. 2005. p.119-131.

Braem, S. Le nécessaire développement théorique de la notion de Profissionannalité pour la Sociologie des Professions française. Interim Conference of ISA Research Committee Sociology of Professional Groups RC 52, Instituto Superior das Ciências do trabalho e da empresa, Lisboa, 2000.

Brasil. Matriz Curricular Nacional: Para Formação em Segurança Pública. Brasília: Ministério da Justiça, 2003.

Brasil. Plano Nacional de Segurança Pública: o Brasil diz não à violência. Brasília: Ministério da Justiça, 2001.

Demailly, Lise (1987). La qualification ou la compétence professionnelle dês enseignants. Sociologie du Travail, XXIX (1), 1987. p. 59-69.

Dubar, Claude. La qualification à travers les jounées de Nantes. Sociologie du Travail, XXIX (1), 1987. p. 314.
Hoyle, Eric. Professionalization and desprofessionalization in education. In Eric Hoyle \& Jacquetta Magerry (Orgs.). World yearbook of education 1980: professional development of teachers. London: Kogan, 1980. p. 42-54.

Jacondino, Eduardo Nunes. A construção micropolítica da profissionalização da segurança pública nas sociedades democráticas. XXVIII Congresso Internacional da ALAS. UFPE: Recife-PE, 2011.

Kuhn, Thomas. A estrutura das revoluções científicas. São Paulo: Perspectiva, 1988. Ed. original americana, 1962

Monjardet, Dominique. O que faz a polícia: sociologia da força pública. Tradução Mary Amazonas Leite de Barros. Ed. Ver. São Paulo: Universidade de São Paulo, 2003.

Muniz, Jaqueline. A Crise de Identidade das Polícias Militares Brasileira: Dilemas e Paradoxos da Formação Educacional. Security and Defense Studies Review. USA, v.01. 2001.p. 177-198.

Poncioni, Paula. O modelo policial profissional e a formação profissional do futuro policial nas academias de polícia do Estado do RL. Sociedade e Estado, Brasília, v. 20, n. 3, set/dez. 2005. p. 585-610.

Poncioni, Paula. Tendências e desafios na formação profissional do policial no Brasil. Revista Brasileira de Segurança Pública. v.1, n.1, 2007. p. 22-31.

Roldão, Maria do Céu. Profissionalidade docente em análise - especificidades dos ensinos superior e não superior. Revista NUANCES, v.13, 2005. p. 108-126.

Roldão. Função docente: natureza e construção do conhecimento profissional. Revista Brasileira de Educação, v.12, n. 34, jan./abr, 2007. p. 94-181.

Sacristán, José Gimeno. Consciência e ação sobre a prática como libertação profissional dos professores. In: NÓVOA, Antonio. (org.). Profissão Professor. Porto Editora, 1995.

Souza, B. D. O Ensino Policial e a Formação de Oficiais na Academia de Polícia Militar do Estado de Goiás. 2003. Dissertação (Mestrado em Educação) Pontifícia Universidade Católica de Goiás, Goiânia, 2003.

Veiga, Ilma Passos Alencastro. Docência: uma construção ético-profissional / Ilma Passos Alencastro Veiga, José Carlos Souza Araújo e Célia Kapuziniak. Campinas: Papirus, 2005.

Veras, João Batista Rosendo. Docência na Polícia Militar do Ceará: Curso de Formação de Soldados de Fileiras (Turma 2007). Dissertação de Mestrado em Educação, apresentada a UEE/CE, 2008, 193pp.

\section{Agradecimentos}

À Coordeção de Aperfeiçoamento Pessoal de Nível Superior (CAPES) pelo financiamento da pesquisa e aos Professores e integrantes do PPGE pelo constante apoio e incentivo à pesquisa. Aos Gestores da ACIDES/SDS e da PMPE pela compreensão, incentivo e apoio ao desenvolvimento da pesquisa na Instituição e à qualificação profissional dos seus integrantes, que retribuirei com muita dedicação ao serviço policial. 